\title{
Mesocrystals and Nonclassical Crystallization
}

\subsection{Introduction}

This chapter presents a history of observations that crystallization can go well beyond the simple 'expected' behaviour found in the salt cellar or when you buy a chemical. Biomorphs, crystal gardens, 'crystal souls', but also the remarkable pattern and structures of biominerals made researchers think that there is something beyond the concept of the bare three-dimensional regularity of molecules. This chapter introduces the beauty and diversity of 'old knowledge'.

Crystallization is the most elementary step in the handling of solid compounds. Crystallization is used for purification or isolation, but crystallization also creates order and beauty. It is presumably no exaggeration that the beauty of crystals has brought humankind to think in categories of substances and molecules. Although crystallization is well known, it is astonishing how little we know about this most elemental process between molecules, and their self-organization.

Of course, there is a classical view on crystallization, presented in textbooks [1] and a plethora of scientific articles. But how much do we really know, and how many original observations have been forgotten in the effort to arrange and compact our knowledge, creating the classical crystallization theory?

In the early days of chemistry, people were quite open in their views and differentiated little between biology and inorganic chemistry, and indeed many similarities have been observed. The first work on a chemical approach to address the morphological complexity of biominerals that we are aware of is the 1873 work of Peter Harting on the morphological complexity of calcium carbonate crystals synthesized in oyster marrow. His schematic drawings are shown in Figure 1.1, highlighting the absence of clear faces 


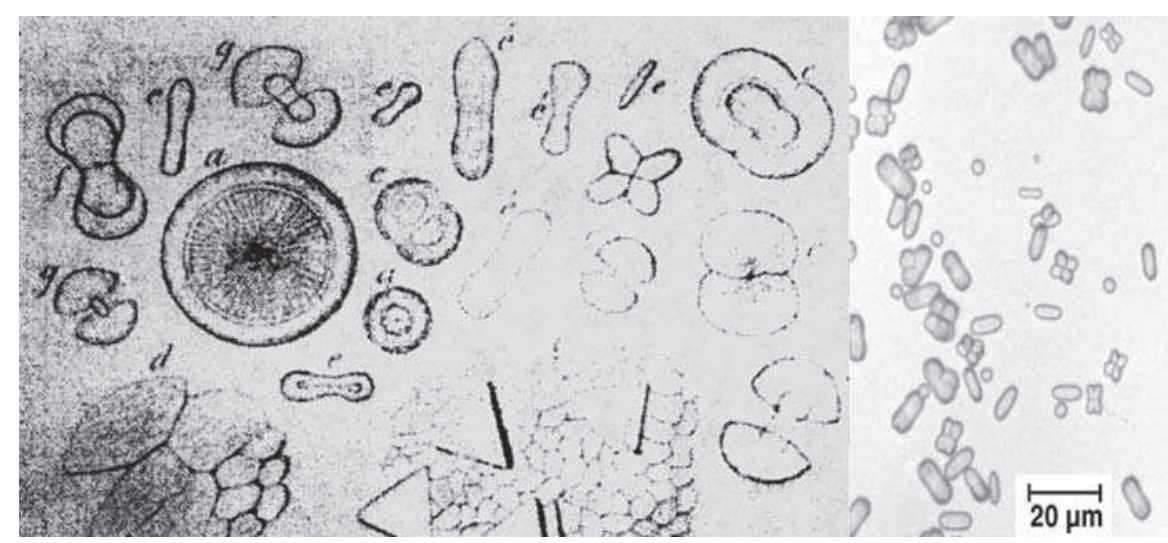

Figure 1.1 Left: $\mathrm{CaCO}_{3}$ crystals obtained via a double diffusion experiment in Oyster marrow [2]. (P. Harting, Recherches de morphologie synthetique sur la production artificielle de quelques formations calcaire organiques, van der Post, Amsterdam, 1872). Right: $\mathrm{CaCO}_{3}$ synthesized in a double jet reactor in presence of $1 \mathrm{~g} / \mathrm{l}$ (PEG-b-PEI-COC ${ }_{17} \mathrm{H}_{35}$ $\left(\mathrm{CH}_{2}-\mathrm{COOH}\right)_{n}$ ) [3]. (M. Sedlak and H. Cölfen, Macromolecular Chemistry and Physics, 2001, 202, 587).

and the appearance of curvature, properties that are classically not attributed to crystalline matter. We parallel this traditional drawing with an actual photograph, which depicts many of the described morphologies mimicked by synthetic processes, as they will be described later in the book. It is clear that the observation of such structures made people suspect that there were no clear borderlines between biology and dead inorganic matter.

In his book Kristallseelen Studien über das anorganische Leben [4], the philosopher and biologist Ernst Haeckel tried to approach the interplay between crystallography and biological structure formation. He carefully observed the complexity of crystallization with and without biomolecules and coined such notations as 'living crystal field' and 'diseased crystals', which (also from a modern view) hit the effects to be described in the very heart, but sound 'nonscientific' in today's language. Haeckel was presumably the first to compile the evidence that the amazing complexity of biominerals can be, to some extent, mimicked in vitro with rather simple ingredients.

The colloid chemist Herbert Freundlich devoted in his book [5] no less than two chapters on crystallization and its dependence on additives. Freundlich described nucleation agents and nucleation inhibitors, binodal crystallization and spinodal processes (the latter being long forgotten afterwards), as well as 'little facts' such as that dyes which are able to stain an inorganic crystal can also inhibit its crystallization. In the book, the first full synthetic experiments for synthesis of morphology (morphosynthesis) found entry, where the shapes of $\mathrm{AgCl}$ crystals were modified by adsorption of methylene blue [6].

The actual versions of all these experiments will be discussed in more detail later in this book; it is just amazing how similar the thinking and experimental approaches were in those days. The main improvement is not the mindset, but only the existence of much 

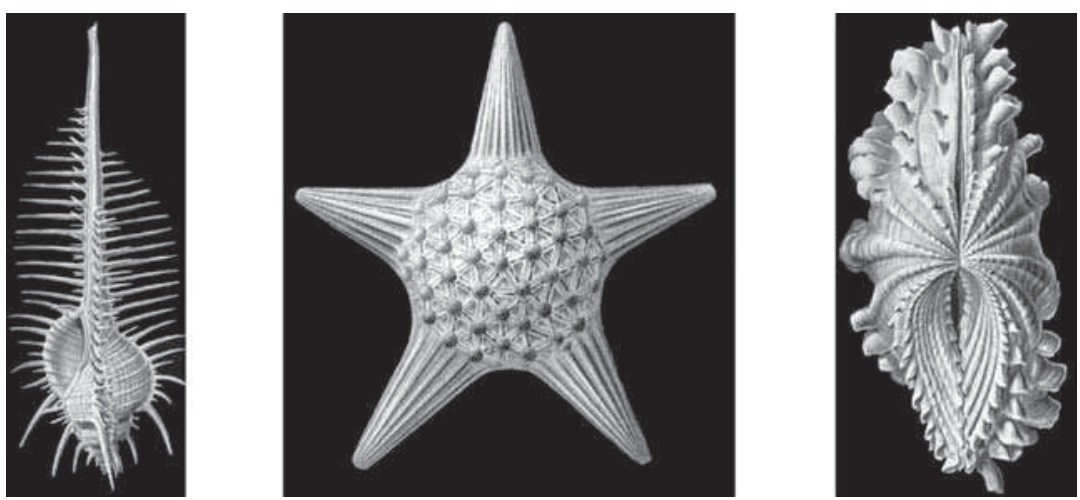

Figure 1.2 Various biominerals with complex forms. Left: Prosobranchia, center: Thalamophora, right: Acephala. (From Ernst Haeckel, Kunstformen der Natur, 1899 - 1904. http://www.zum.de/stueber/haeckel/kunstformen/natur.html. Copyright 1999, Kurt Stueber and Max-Planck-Institut für Züchtungsforschung).

better analytical tools, which have enabled us to grab the details of these unconventional crystallization processes.

Maybe better known in the English speaking world, the Scottish zoologist D'Arcy Thompson published his historic book, On Growth and Form [7], in 1917, referring actually to the extensive work of Haeckel. Thompson used his classical and mathematical training for an integrative approach to describe biological structural motifs, including biominerals. A point that influenced his book very seriously is that he was able to show that most biological complexity still follows very strict physico-chemical rules, partly given by the growth process, and partly driven by mechanical demands on the biomaterials that underlie evolutionary optimization pressure.

It is the topic of this book to clarify how such complex crystallization processes can be controlled. Collected evidence will be presented that beside classical crystallization treated in former textbooks there is a second 'reaction channel' that works via parallel crystallization towards amorphous intermediates and then crystalline nanostructures, which act as material deposits or intermediates for arrangement and densification towards the final structure. This way, crystallization gains the freedom and possibilities to generate complex forms, but also mineral heterostructures, gradient materials, and organic/inorganic nanohybrids are brought to the hands of humankind.

Due to the importance of organized self-assembly and the many formal similarities to the formation of organized mesophases, we will call these structures mesocrystals, as an abbreviation of mesoscopically structured crystal, and the process of parallel crystallization, colloidal assembly, and controlled structure formation, mesocrystallization.

In this analysis, much has been and still can be learned from the processes of biomineralization, leading to those well-defined organic inorganic hybrid materials with superior material properties, complex morphologies and hierarchical order [8 10$]$. Biominerals are often iso-oriented crystal structures with amazingly complex morphologies, like the hammer-shaped building units of coccoliths [11] or the skeletal plates of sea urchins [12]. Although it is known that organic templates, as in the case for 
coccoliths, play an important role [11], the actual crystallization mechanism of the inorganic phase in many biominerals remained largely unexplored.

Recently, increasing evidence was found that biomineralization also takes place via the colloidal pathways of meso-crystallization. Amorphous precursor particles, for instance, as reported for sea urchin spines [13], allow the storage of large amounts of materials in metastable precursor particles, which are readily available to a crystallization event in a confined reaction environment. Advantages of this crystallization pathway are highly efficient mass fluxes independent of ion products, the coupled high crystallization speeds, and crystallization without changes in the $\mathrm{pH}$ and the osmotic pressure, key features for mineralization, especially in biological systems. This is set in strong contrast to the possibilities of classical crystallization, which postulates an ion-by-ion or single molecule attachment to a critical crystal nucleus and is therefore bound to solubility products and diffusion limitations.

These particle mediated crystallization pathways are thus a nonclassical crystallization process involving mesoscopic transformation of self-assembled, metastable or amorphous precursor particles into nanoparticulate superstructures [14,15], as recently reviewed [16]. By mesoscale transformation, not only single oriented crystals with complex morphologies, but also superstructures of nanoparticles interspaced by organic additives can be formed. Their fusion leads to apparently single crystalline, isooriented structures with included organic additives as defects and sometimes also the leftovers of the prior amorphous phases. Support for this view comes from biomineral examples, which although apparently single crystalline often contain minor amounts of included biopolymers. This inclusion cannot be understood from the viewpoint of an ion-mediated crystallization process, as additives in this mechanism are generally considered to adsorb at edges and kinks in the developing crystal surface, stopping it from further growth [17]. (see also Figure 2.7).

Mesocrystal formation and the process of mesoscale transformation are, however, not restricted to biominerals, thus motivating this book. It looks like Nature makes use of an advantageous physico-chemical construction principle, gaining speed and flexibility of construction. In synthetic systems, similar inclusions of additives up to $30 \mathrm{wt}$. $\%$ were observed in as-grown crystals, too [18 20]. Revisiting the older literature shows that comparable observations were made in synthetic inorganic chemistry much earlier, even in the absence of additives [21 24], and the relevant question arises as to which role precursor particles and their superstructures play at least as intermediates in crystallization in general.

We also want to note that the term "mesocrystal" has been used before in the literature, but in the less restricted sense of a mutual three-dimensional translational ordering of various nanocrystals. As templates, pore systems of the MCM 41 type were used for the deposition of quantum sized $\mathrm{BaTiO}_{3}$ [25 27] or $\mathrm{SrBi}_{2} \mathrm{Ta}_{2} \mathrm{O}_{9}$. [26,28] Our definition is more restricted as it also involves, besides translational three-dimensional order, orientational order (vectorial alignment), and spontaneous self-assembly towards normally facetted microstructures.

Besides the interesting scientific question of formation mechanisms and the superior properties of the resulting materials, it is admittedly also a big bonus for this field that mesocrystals are simply beautiful and esthetically appealing. The fascination for objects with complex shapes has always been an integral part of the cultural heritage of 
humankind and constitutes inspiration as well as a driving force in architecture, art and also science. The morphological diversity and complexity of naturally occurring forms and patterns has been a motivation for humans to copy Nature to achieve functional, esthetic, and societal value. [29] Although natural materials are often characterized by a finely carved appearance of remarkable aesthetical form, their formation is mostly directed by stringent selection processes, in order to provide efficiency and superior function [30].

Often, the non-classical nature of crystalline assemblies is not recognized, especially when they scatter X-rays and electrons like single crystals, which makes it difficult to assign mesocrystallization experiments described in the literature unequivocally. It is therefore the main task of this book to close this knowledge gap, to go beyond classical crystallization and to show that both crystallization pathways, particle-mediated and molecule-mediated, are in fact part of a common unifying crystallization scenario. Therefore, our book is structured into main chapters describing the classical crystallization theories and possibilities for crystal morphogenesis (Chapter 2), crystals challenging the classical textbook view on crystallization (Chapter 3), and nonclassical particle-mediated crystallization pathways (Chapter 4). Afterwards, we will give the foundations for the understanding of particle-mediated crystallization processes and mesocrystal formation. These include a treatment of self-organization processes (Chapter 5), colloidal crystals (Chapter 6), and the mesocrystal concept and properties (Chapter 7), including a description of the mesocrystals described so far sorted by their preparation and main occurrence. We will then try to capture the current existing knowledge about the formation mechanisms of mesocrystals (Chapter 8), as well as the analytical tools used to study mesocrystals (Chapter 9) and discuss the possibilities for the tuning of mesocrystal properties (Chapter 10). This will be summarized with the description of a unifying crystallization scenario combining classical and nonclassical crystallization (Chapter 11). This unifying crystallization scenario will allow, at least, for a phenomenological understanding of the crystallization phenomena described in this book. We will finally point out the analogy between hierarchically structured crystals and biopolymers, as well as oriented aggregation and polymers (Chapter 12) to show that a clear distinction between the living organic world and nonliving inorganic world cannot be made, which goes back to the initial views on this subject of people like Haeckel. Finally, we will end with a summary and outlook of possible future research directions (Chapter 13).

We have structured each of the main chapters in such a way that a short summarizing introduction for the general reader is given at the beginning of each chapter. This will enable the fast pick up of the main ideas discussed in the specific chapter, although each chapter also contains detailed material for the specialist or those readers who want to obtain extended knowledge in the described area. The chapters will also give relevant primary literature for more in-depth study of the subjects. Although our book, in view of the rapid development of this research area, has obviously no chance to be really comprehensive, it has at least been tried to capture the most recent developments and current knowledge. It is therefore hoped that this book will further stimulate research in this new and very exiting area, especially in view of the huge scientific and industrial relevance of crystallization processes and their control. 


\section{References}

1. J. W. Mullin, Crystallization, 4th edn., Butterworth Heinemann, Oxford, 2001.

2. P. Harting, Recherches de morphologie synthétique sur la production artificielle de quelques formations calcaires organiques, van der Post, Amsterdam, 1872.

3. M. Sedlák and H. Cölfen, Macromolecular Chemistry and Physics 2001, 202, 587.

4. E. Haeckel, Kristallseelen: Studien uber das anorganische Leben (Crystal Souls: Studies on Inorganic Life), 3rd edn., Kröner, Leipzig, 1925.

5. H. Freundlich, Kapillarchemie: eine Darstellung der Chemie der Kolloide und verwandter Gebiete, 3rd edn., Akademische Verlagsgesellschaft, Leipzig, 1923.

6. W. Reinders, Zeitschrift fur physikalische Chemie Stochiometrie und Verwandtschaftslehre 1911, 77, 677.

7. D. A. W. Thompson, On Growth and Form, abridged edn., Cambridge University Press, Cambridge, 1966.

8. H. A. Lowenstam and S. Weiner, On Biomineralization, Oxford University Press, New York, 1989.

9. W. Bäuerlein, Biomineralization, Progress in Biology, Molecular Biology and Application, 2nd completely revised and extended ed., Wiley VCH, Weinheim, 2004.

10. S. Mann, Biomineralization, Principles and Concepts in Bioinorganic Materials Chemistry, Oxford University Press, Oxford, 2001.

11. M. E. Marsh, in Biomineralization, Progress in Biology, Molecular Biology and Application, 2nd completely revised and extended edition edn., Wiley VCH, Weinheim, 2004, p. 197.

12. G. Donnay and D. L. Pawson, Science 1969, 166, 1147.

13. Y. Politi, T. Arad, E. Klein, S. Weiner, and L. Addadi, Science 2004, 306, 1161.

14. H. Cölfen and M. Antonietti, Angew. Chem. Int. Ed. 2005, 44, 5576.

15. H. Cölfen, in Biomineralization: From Paleontology to Materials Science, (eds. J. L. Arias and M. S. Fernandez), Editorial Universitaria, Universidad de Chile, Santiago, 2006.

16. H. Cölfen and S. Mann, Angew. Chem. Int. Ed. 2003, 42(21), 2350.

17. G. Wegner, P. Baum, M. Müller, J. Norwig, and K. Landfester, Macromolecular Symposia 2001, $175,349$.

18. S. H. Yu and H. Cölfen, J. Mater. Chem. 2004, 14, 2124.

19. L. Qi, H. Cölfen, and M. Antonietti, Ang. Chem. Int. Ed, 2000, 39, 604.

20. A. Taubert, D. Palms, O. Weiss, M. T. Piccini, and D. N. Batchelder, Chemistry of Materials 2002, 14, 2594.

21. H. Zocher and W. Heller, Zeitschrift fur Anorganische und Allgemeine Chemie 1930, 186, 75.

22. W. Heller, Comptes Rendus Hebdomadaires des Seances de L'Academie des Sciences 1935, 201, 831.

23. E. Matijevic and P. Scheiner, J. Coll. Interface Sci. 1978, 63, 509.

24. W. P. Hsu, L. Rönnquist, and E. Matijevic, Langmuir 1988, 4, 31.

25. K. Yamada and S. Kohiki, Physica E 1999, 4, 228.

26. S. Kohiki, S. Takada, A. Shimizu, K. Yamada, H. Higashijima, and M. Mitome, J. Appl. Phys. 2000, 87, 474.

27. S. Kohiki, S. Takada, K. Yamada, Y. Adachi, A. Shimizu, M. Oku, and M. Mitome, Physica E 1999, 5,161

28. H. Higashijima, S. Kohiki, S. Takada, A. Shimizu, and K. Yamada, Appl. Phys. Lett. 1999, 75, 3189.

29. S. Mann, Angew. Chem. Int. Ed. 2000, 39, 3392.

30. C. Sanchez, H. Arribart, and M. M. Giraud Guille, Nat. Mater. 2005, 4, 277. 